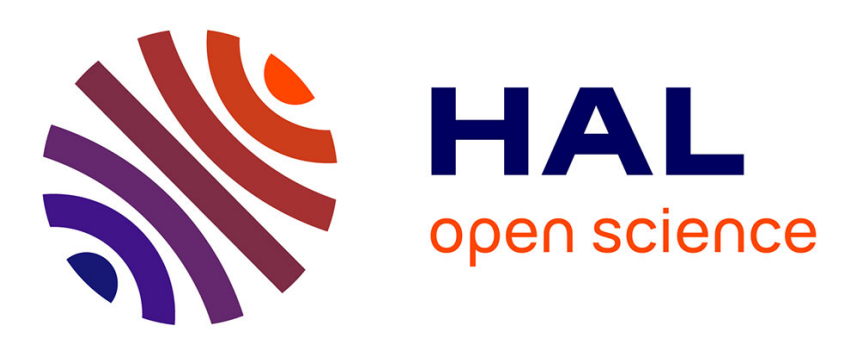

\title{
Impact of tungsten recrystallization on ITER-like components for lifetime estimation
}

Alan Durif, Marianne Richou, G. Kermouche, Matthieu Lenci, Jean-Michel Bergheau

\section{- To cite this version:}

Alan Durif, Marianne Richou, G. Kermouche, Matthieu Lenci, Jean-Michel Bergheau. Impact of tungsten recrystallization on ITER-like components for lifetime estimation. Fusion Engineering and Design, 2019, 138, pp.247-253. 10.1016/j.fusengdes.2018.11.003 . emse-02892621

\section{HAL Id: emse-02892621 \\ https://hal-emse.ccsd.cnrs.fr/emse-02892621}

Submitted on 9 Sep 2021

HAL is a multi-disciplinary open access archive for the deposit and dissemination of scientific research documents, whether they are published or not. The documents may come from teaching and research institutions in France or abroad, or from public or private research centers.
L'archive ouverte pluridisciplinaire HAL, est destinée au dépôt et à la diffusion de documents scientifiques de niveau recherche, publiés ou non, émanant des établissements d'enseignement et de recherche français ou étrangers, des laboratoires publics ou privés.

\section{(c)(1)}

Distributed under a Creative Commons Attribution| 4.0 International License 


\title{
Impact of tungsten recrystallization on ITER-like components for lifetime estimation
}

 \\ ${ }^{a}$ CEA, IRFM, F-13108 Saint-Paul-Lez-Durance, France \\ b École Nationale Supérieure des Mines de Saint-Étienne, LGF, CNRS UMR 5307, 42023 Saint-Etienne cedex 2, France \\ ${ }^{\mathrm{c}}$ University of Lyon, Ecole Nationale d' Ingénieurs de Saint-Etienne, LTDS, CNRS UMR 5513, 42023 Saint-Etienne, France
}

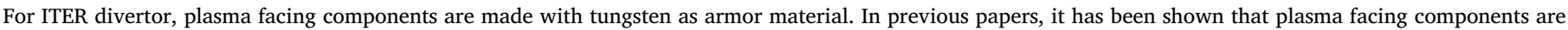

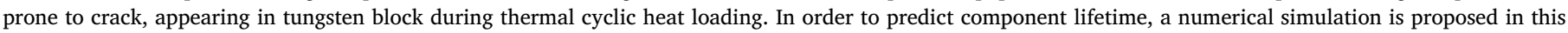

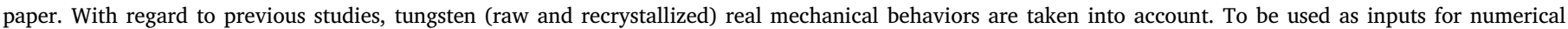

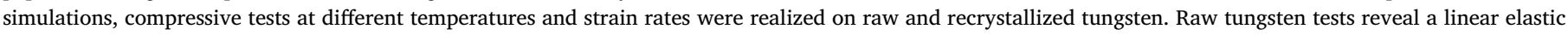

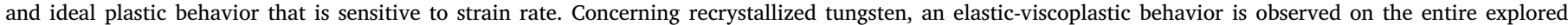

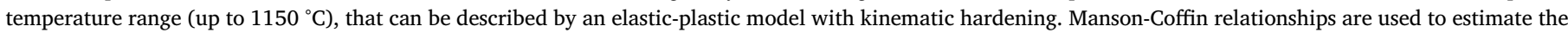

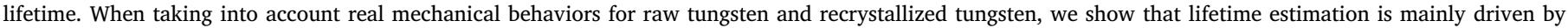
recrystallized thickness in the component, by the ductile to brittle transition temperature and finally by strain rate.

\section{Introduction}

The fusion reaction could become a viable way to generate electricity. To perform this reaction, reactors confine magnetically plasma in a vacuum chamber. However, plasma confinement is imperfect and due to the magnetic plasma configuration, energy losses are directed toward the main wall, mainly on the lower part of the vessel called divertor. For the ITER divertor, plasma facing components have to withstand cyclic high heat flux (stationary and transient) up to $20 \mathrm{MW} /$ $\mathrm{m}^{2}[1]$. High Heat Flux (HHF) experimental campaigns were performed [2] and proved that actively cooled plasma facing components made with tungsten as armor material, bonded on a copper alloy tube as heat sink structural material are able to satisfy the ITER heat exhaust requirements $\left(20 \mathrm{MW} / \mathrm{m}^{2}\right)$ [3]. However, due to high heat flux, strong temperature gradients are generated on a thickness of $7 \mathrm{~mm}$, leading to extreme temperature values from $2000^{\circ} \mathrm{C}$ at the loaded surface to $500{ }^{\circ} \mathrm{C}$ near the cooling tube [4]. $2000{ }^{\circ} \mathrm{C}$ is large enough to alter the tungsten microstructure causing recrystallization and mechanical properties losses and then damages such as macro cracks in the material [2,5-7]. It is thus necessary to identify which phenomena have to be taken into account to predict the lifetime of tungsten armored component, this identification is the aim of this paper. M. Li et al. pointed out that recrystallization is a key phenomenon regarding lifetime prediction $[8,9]$. Indeed, they show that the loss of mechanical properties induced by recrystallization leads to an increase of plastic strain increment per thermal cycle. From Manson-Coffin relationship they conclude on the drastic reduction of the component lifetime. However, thermomechanical model uses by assumption an linear elastic and ideal plastic behavior for recrystallized tungsten. In this paper, it is proposed to investigate the effect of the actual mechanical behavior of tungsten grades (in recrystallized and no recrystallized states) on lifetime prediction. For this, the model proposed by M. Li et al. [8] is used and assumed mechanical behaviors of tungsten are replaced by the actual ones. In the first part of this paper, compressive tests of raw and recrystallized tungsten for different temperatures and strain rates are presented. The thermomechanical model is then described. Numerical simulations are performed to estimate the equivalent plastic strain increments depending on various parameters: thickness of the recrystallized layer and constitutive relations. Manson-Coffin relations are used to estimate the number of cycles to failure. A conclusion is

\footnotetext{
** Principal corresponding author.

* Corresponding author.

E-mail addresses: alan.durif@cea.fr (A. Durif), marianne.richou@cea.fr (M. Richou).
} 


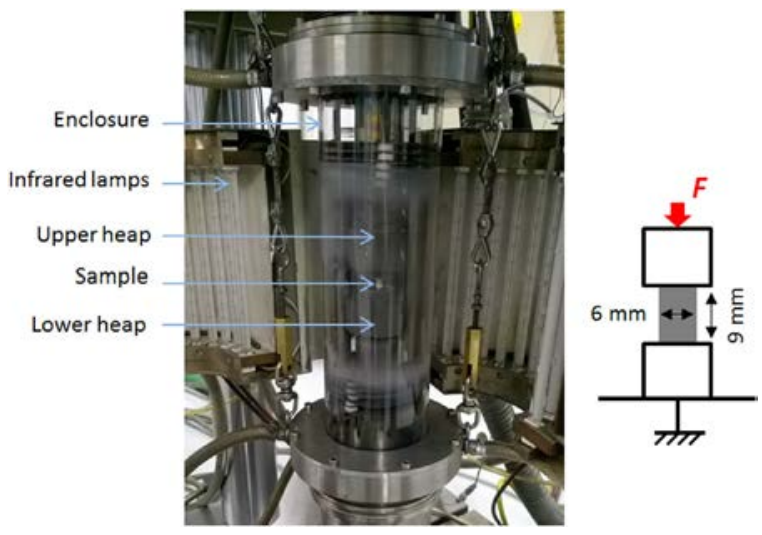

Fig. 1. Compressive test device.

finally brought on the key parameters that govern the lifetime prediction of plasma facing components.

\section{High temperature compressive tests}

\subsection{Materials and methods}

ITER requirements request tungsten manufacturers to supply material with strong grains orientation [3]. Usually, oriented microstructure is obtained by a forming or rolling process. Rolling process involves grain orientation, strain rate sensitivity and promotes tungsten recrystallization. Microstructure change, such as recrystallization, decreases significantly the mechanical properties of the material [10]. Compressive tests are thus performed on rolling tungsten provided by Advance Technology and Materials (AT\&M) which is one of the ITER tungsten grade suppliers. Tungsten samples are cut from tungsten blocks $\left(28 * 28 * 12 \mathrm{~mm}^{3}\right)$ into cylindrical shape (dimensions are displayed in Fig. 1). 24 samples are prepared. Samples are cut in the transversal direction (T) (Fig. 2) and half of them are then annealed $\left(15 \mathrm{~h}\right.$ at $\left.1350{ }^{\circ} \mathrm{C}\right)$ to obtain a recrystallized microstructure.

Compressive tests are performed using a hydraulic machine (Schenk) on raw and recrystallized tungsten at $500{ }^{\circ} \mathrm{C}, 750{ }^{\circ} \mathrm{C}, 900{ }^{\circ} \mathrm{C}$ and $1150{ }^{\circ} \mathrm{C}$ (Fig. 1). The test device is equipped with an infrared heating system, capable of reaching temperature up to $1200^{\circ} \mathrm{C}$ and an enclosure to perform compressive tests under argon atmosphere. Argon is used to avoid oxidation on surfaces samples. For each test, sample is coated by spray with graphite and boron in order to avoid friction during the compression. Then, sample is placed in the enclosure on TZM (Tungsten-zircon-molybdenum) heaps. Two thermocouples are

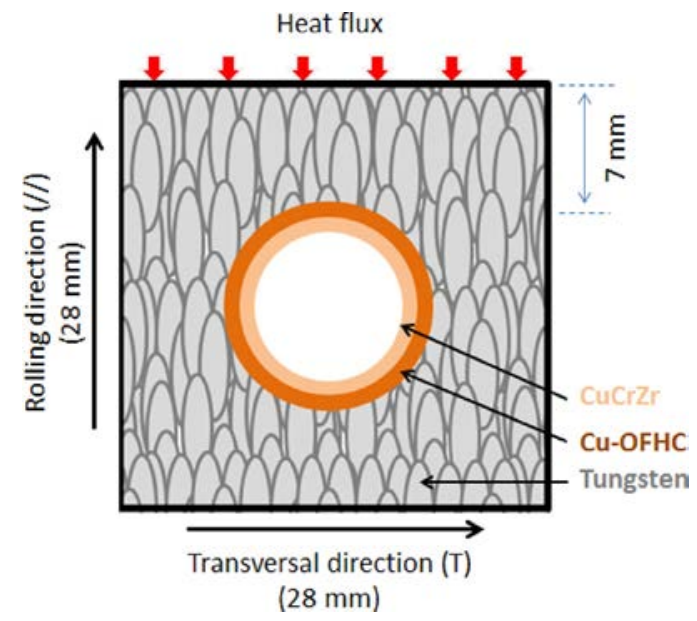

Fig. 2. Theoretical grain microstructure on rolling tungsten block. placed in a fixed position on the test line, at the sub-surface in the heaps, close to each of the faces of the sample to measure sample temperature. Once samples reached test temperatures, they were maintained $10 \mathrm{~min}$ to ensure a homogeneous temperature in the whole sample. Compressive tests were performed for several strain rates for the same temperature range. For each test, constant strain rate is obtained assuming a constant volume and a homogeneous deformation of the sample during the test. Strain rates were chosen based on the expected thermal strain rate $\left(\dot{\varepsilon}^{\text {th }}\right)$ under stationary thermal heat flux in ITER (Eq. (1)):

$\dot{\varepsilon}^{\text {th }}=\frac{\left(T_{s}-T_{0}\right)^{*} \alpha\left(T_{s}\right)}{\Delta t}$

where $T_{s}$ corresponds to the block surface temperature and $\alpha$ corresponds to the thermal expansion coefficient $\left(5.08 \times 10^{-6} \mathrm{~K}^{-1}\right.$ at $1400{ }^{\circ} \mathrm{C}$ [10]). Previous simulations [4] show that at $20 \mathrm{MW} / \mathrm{m}^{2}$, the surface temperature can reach up to $1400^{\circ} \mathrm{C}$ in approximately $1.2 \mathrm{~s}$ $(t=1.2 \mathrm{~s}) . T_{0}$ is representative of the initial temperature of the tungsten block under cooling condition before plasma shock $\left(T_{0}=120^{\circ} \mathrm{C}\right)[8]$. Finally, strain rate is estimated around $6 \times 10^{-3} \mathrm{~s}^{-1}$. Also, fast transient heat loadings are expected in ITER [11]. These particulars heat loadings (edges localized modes) have strong impact on the tungsten surface temperature. In this context, it was decided to test samples also at higher strain rates $\left(6 \times 10^{-2} / \mathrm{s}\right.$ and $\left.6 \times 10^{-1} / \mathrm{s}\right)$.

\subsection{Results}

In Fig. 3, stress-strain curves are plotted for $500^{\circ} \mathrm{C}$ (at $6 \times 10^{-3} \mathrm{~s}^{-1}$ ) and $1150^{\circ} \mathrm{C}$ (at $6 \times 10^{-3} \mathrm{~s}^{-1}$ and $6 \times 10^{-1} \mathrm{~s}^{-1}$ ). Curves reveal that tungsten is ductile between $500^{\circ} \mathrm{C}$ and $1150{ }^{\circ} \mathrm{C}$ and that tungsten has a linear elastic and ideal plastic behavior. Moreover, yield stresses (estimated at $0.2 \%$ ) decrease from $559 \mathrm{MPa}$ at $500{ }^{\circ} \mathrm{C}$ to $426 \mathrm{MPa}$ at $1150^{\circ} \mathrm{C}$, showing that temperature has an impact on tungsten mechanical property. Also, strain rate effect is observable, indeed, yield stresses (estimated at $0.2 \%$ ) decrease from $459 \mathrm{MPa}$ at $6 \times 10^{-1} \mathrm{~s}^{-1}$ to $426 \mathrm{MPa}$ at $6 \times 10^{-3} \mathrm{~s}^{-1}$. To conclude, Fig. 3 highlights that raw tungsten recrystallizes dynamically at $1150^{\circ} \mathrm{C}$ (at $6 \times 10^{-3} \mathrm{~s}^{-1}$ ). In this case, once the tungsten reached the yield stress, a stress decrease is noticed during the test.

In Fig. 4, stress-strain curves are plotted for $500{ }^{\circ} \mathrm{C}$ at $6 \times 10^{-3} \mathrm{~s}^{-1}$ and $1150^{\circ} \mathrm{C}$ (at $6 \times 10^{-3} \mathrm{~s}^{-1}$ and at $6 \times 10^{-1} \mathrm{~s}^{-1}$ ). Recrystallized tungsten is ductile between $500{ }^{\circ} \mathrm{C}$ and $1150^{\circ} \mathrm{C}$. This clearly involves that Ductile to Brittle Transition Temperature (DBTT) is below $500^{\circ} \mathrm{C}$. In the literature, several tungsten grades were studied and large differences were obtained concerning the estimation of the DBTT $[12,13]$. In a further study this effect will be studied. The increase of temperature has a strong impact on mechanical properties of recrystallized tungsten. Yield stress (estimated at $0.2 \%$ ) decreases from $61 \mathrm{MPa}$ at

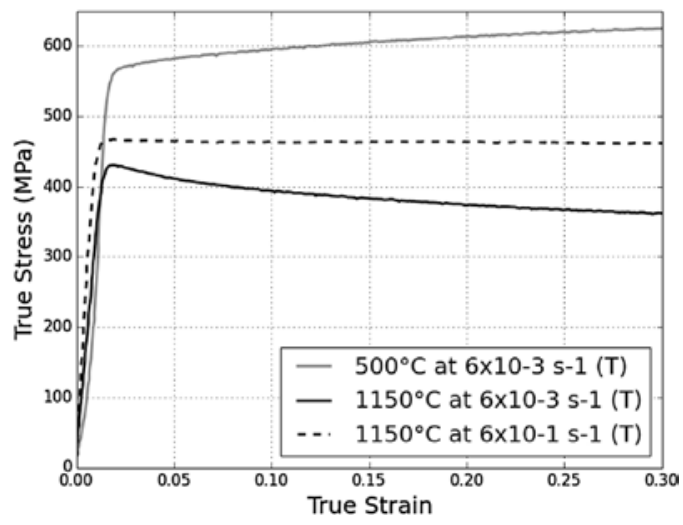

Fig. 3. Stress-strain curves obtained on raw tungsten at $500{ }^{\circ} \mathrm{C}$ at $6 \times 10^{-3} \mathrm{~s}^{-1}$ and $1150{ }^{\circ} \mathrm{C}$ obtained at $6 \times 10^{-3} \mathrm{~s}^{-1}$ and $6 \times 10^{-1} \mathrm{~s}^{-1}$. 




Fig. 4. Stress-strain curves obtained on recrystallized tungsten at $500{ }^{\circ} \mathrm{C}$ (at $6 \times 10^{-3} \mathrm{~s}^{-1}$ ) and $1150{ }^{\circ} \mathrm{C}$ (at $6 \times 10^{-3} \mathrm{~s}^{-1}$ and at $6 \times 10^{-1} \mathrm{~s}^{-1}$ ).

$500{ }^{\circ} \mathrm{C}$ to $49 \mathrm{MPa}$ at $1150^{\circ} \mathrm{C}$. Contrary to the linear elastic and ideal plastic case, described for raw tungsten, recrystallized tungsten exhibit a strong hardening. Once the yield stress is attained; stress has to be endlessly increased to ensure plastic strain. Tangent moduli obtained are presented in Table 2. Tangent modulus corresponds to the plastic (hardening) slope of the material. In this paper, slope are measured between strain corresponding to yield stress (estimated at $0.2 \%$ ) and expected strain after 3 thermal cycles at $20 \mathrm{MW} / \mathrm{m}^{2}$ estimated at $2.3 \%$ in [8]. Recrystallized tungsten is also sensitive to strain rate. Same quantitative results are obtained for each studied temperature. These observations lead to conclude that recrystallized tungsten has elasticviscoplastic behavior.

Here below, correlation of obtained mechanical characteristics with other published characteristics [14] is presented. In Table 1, yield stresses and stresses values obtained at $0.2 \%$ at $750{ }^{\circ} \mathrm{C}$ (representative of the described compressive test obtained at $6 \times 10^{-3} \mathrm{~s}^{-1}$ on raw tungsten) and at $800^{\circ} \mathrm{C}$ [14] (obtained on AT\&M tungsten grade during tensile test at $10^{-4} \mathrm{~s}^{-1}$ ) are presented. Comparable yield stresses $(=5 \%)$ are obtained, revealing that plastic constitutive relation obtained in compression are representative to that obtained in traction.

\section{Finite element analysis}

\subsection{Geometry, meshing}

Geometry presented in Fig. 5, is representative of an ITER divertor block. Thanks to the use of two symmetry planes only quarter part block is modeled. Dimensions are identical to the ones implemented in the numerical model used by M. Li et al. [8] $\left(28 * 14 * 6 \mathrm{~mm}^{3}\right)$. Tungsten block dimension is $28 \mathrm{~mm}$ (width) $* 28 \mathrm{~mm}$ (height) $* 12 \mathrm{~mm}$ (depth). The minimum distance from tungsten upper surface to the copper interlayer is $6.5 \mathrm{~mm}$. Tube inner diameter is $12 \mathrm{~mm}$, while the outer diameter of the tube is $15 \mathrm{~mm}$. The thickness of the Cu-OFHC interlayer is $1 \mathrm{~mm}$. ANSYS 17.2 commercial finite element analysis code is used to perform this geometry. 12952 quadratic elements are used to mesh the 3D geometry.

Table 1

Raw tungsten mechanical properties obtained under compressive and tensile tests.

\begin{tabular}{lll}
\hline & $\begin{array}{l}\text { Tensile test }[14] \\
\left(800{ }^{\circ} \mathrm{C}, 10^{-4} \mathrm{~s}^{-1}\right)\end{array}$ & $\begin{array}{l}\text { Compressive test } \\
\left(750^{\circ} \mathrm{C}, 6 \times 10^{-3} \mathrm{~s}^{-1}\right)\end{array}$ \\
\hline Yield stress $(\mathrm{MPa})$ & 579 & 552 \\
Stress at $0.2(\mathrm{MPa})$ & 579 & 553 \\
\hline
\end{tabular}

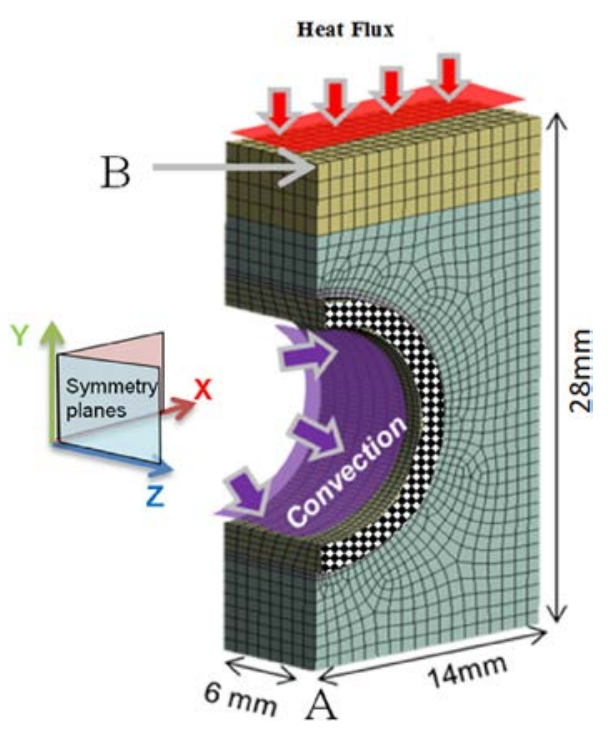

Fig. 5. Numerical model.

Table 2

Material properties.

\begin{tabular}{lllll}
\hline Material & $\begin{array}{l}\text { Temperature } \\
\left({ }^{\circ} \mathrm{C}\right)\end{array}$ & $\begin{array}{l}\text { Strain rate } \\
\left(\mathrm{s}^{-1}\right)\end{array}$ & $\begin{array}{l}\text { Yield stress at } \\
0.2 \%(\mathrm{MPa})\end{array}$ & $\begin{array}{l}\text { Tangent modulus } \\
(\mathrm{MPa})\end{array}$ \\
\hline \multirow{2}{*}{ Raw tungsten } & \multirow{2}{*}{500} & $6 \times 10^{-3}$ & 559 & 0 \\
& \multirow{2}{*}{1150} & $6 \times 10^{-1}$ & 678 & 0 \\
& & $6 \times 10^{-3}$ & 426 & 0 \\
& & $6 \times 10^{-1}$ & 459 & 0 \\
Recrystallized & \multirow{2}{*}{500} & $6 \times 10^{-3}$ & 61 & 5913 \\
Tungsten & \multirow{2}{*}{1150} & $6 \times 10^{-1}$ & 46 & 9618 \\
& & $6 \times 10^{-3}$ & 49 & 3906 \\
& & $6 \times 10^{-1}$ & 58 & 4985 \\
\hline
\end{tabular}

\subsection{Materials properties}

Based on described mechanical tests, raw tungsten is assumed to be linear elastic and ideal plastic (tangent moduli are set to 0 , Table 2). Despite the slight anisotropy effect [14], tungsten is assumed isotropic in this model. Elastic-visoplastic behavior with hardening was observed for recrystallized tungsten. Moreover, in literature [16] cyclic tests were performed on recrystallized tungsten at $800{ }^{\circ} \mathrm{C}$. Constitutive relation obtained revealed kinematic hardening over cycles. To take into account this in our upcoming simulations, kinematic hardening model is used. In stress space, kinematic hardening models allow a translation of the yield surface and hence that cyclic effects like softening, hardening or Bauschinger effect [15] can be modeled. Bilinear kinematic hardening model is used in simulations. This model assumes that the stress-strain curve can be described as two straight line segments. For the elastic part, slope is young modulus and for the plastic part, slope is tangent modulus. Tungsten mechanical properties obtained under compressive tests (yield stress and tangent modulus) used in dedicated simulations are summarized in Table 2. Bold characters presented in upcoming equations denote tensorial quantities. The yield criteria $(f(\sigma$, $\chi)$ ) of bilinear kinematic hardening model used is commonly defined as [20]:

$f(\sigma, \chi)=J(\sigma-\chi)-\sigma_{y}$

With $\chi$ the back stress and $\sigma_{y}$ the material yield stress, both depending on temperature. $J($.) denotes the von Mises invariant. In uniaxial case, $\chi$ is defined as follow:

$\chi=H \varepsilon^{P}$

With $\varepsilon^{P}$ plastic strain and $H$ : 


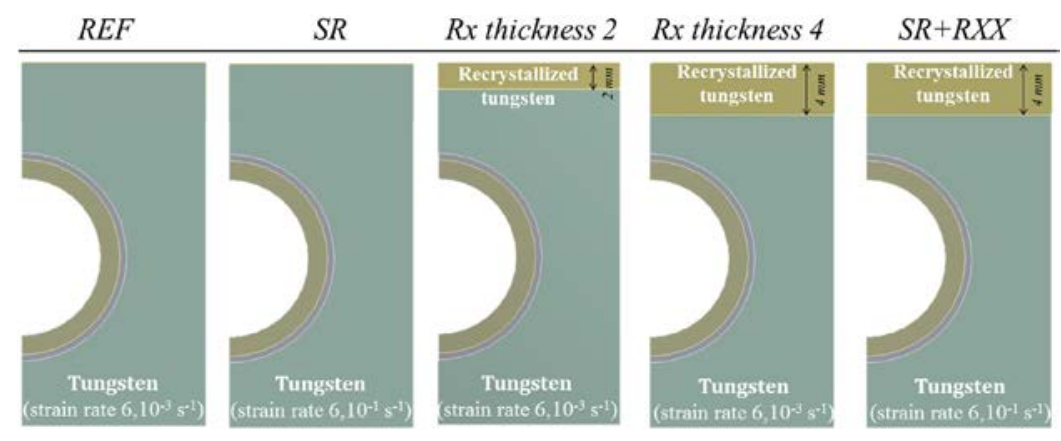

Fig. 6. Simulations.

$H=\frac{\mathrm{EE}_{T}}{E-E_{T}}$

The Young modulus $(E)$, and the tangent modulus $\left(E_{T}\right)$ are temperature dependent.

$E$, heat conductivity and coefficient of thermal expansion used are those presented for the raw tungsten and recrystallized tungsten in [10]. Also, mechanical properties used for $\mathrm{Cu}-\mathrm{OFHC}$ and $\mathrm{CuCrZr}$ are extracted from stress-strain curves presented in [10]. Stresses and strains generated in the both copper materials are not studied.

\subsection{Studied cases}

In this paper, several simulations are performed.

1. The Reference simulation (Ref, Fig. 6) assumes raw tungsten obtained experimentally at $6 \times 10^{-3} \mathrm{~s}^{-1}$ of strain rate.

2. Second simulation which aims to analyse the effect of the strain rate (SR, Fig. 6); assumes raw tungsten and uses mechanical properties obtained experimentally at $6 \times 10^{-1} \mathrm{~s}^{-1}$ of strain rate.

3. Another simulation which aims to analyse the effect of tungsten recrystallization (RXX thickness 2, Fig. 6); assumes $2 \mathrm{~mm}$ thickness of recrystallized tungsten on the upper part of the model. $2 \mathrm{~mm}$ thickness of the recrystallized tungsten is chosen as it is representative to that observed on the center of the block after 300 high heat flux cycles [2]. This model uses, for raw tungsten and recrystallized tungsten, related mechanical properties obtained experimentally at $6 \times 10^{-3} \mathrm{~s}^{-1}$ of strain rate.

4. Another simulation which aims to analyse the effect of tungsten recrystallization thickness (RXX thickness 4, Fig. 6); assumes $4 \mathrm{~mm}$ thickness of recrystallized tungsten on the upper part of the model and uses, for raw tungsten and recrystallized tungsten, related mechanical properties obtained experimentally at $6 \times 10^{-3} \mathrm{~s}^{-1}$ of strain rate. Conservative $4 \mathrm{~mm}$ thickness of the recrystallized tungsten is chosen as it is representative to that observed on the block edge after 300 high heat flux cycles [2].

5. Another simulation which aims to analyse the effect of tungsten recrystallization combined to the effect of strain rate (SR + RXX,) Fig. 6); assumes $4 \mathrm{~mm}$ thickness of recrystallized tungsten on the upper part of the model and uses for raw tungsten and recrystallized tungsten related mechanical properties obtained experimentally at $6 \times 10^{-1} \mathrm{~s}^{-1}$ of strain rate.

\subsection{Boundary conditions and thermal loads}

For comparison, same thermal loads as $\mathrm{M}$. Li et al. are applied on the block upper surface. Convective boundary condition is applied to the cooling pipe inner surface. Schlosser et al routine [17], is used to calculate heat transfer coefficients taking into account coolant conditions (pressure $3.3 \mathrm{MPa}$, temperature $120^{\circ} \mathrm{C}$ and water velocity $12 \mathrm{~m} / \mathrm{s}$ ). Calculated coefficients are presented in Table 3 and are representative of those given by M. Li et al.
Table 3

Representative heat transfer coefficient data used in simulations.

\begin{tabular}{lllllll}
\hline$T\left({ }^{\circ} \mathrm{C}\right)$ & 50 & 100 & 150 & 200 & 250 & 290 \\
\hline $\begin{array}{c}\text { Heat transfer coefficient }(\mathrm{kW} / \\
\left.\mathrm{m}^{2}{ }^{\circ} \mathrm{C}\right)\end{array}$ & 98.6 & 108.2 & 115.0 & 120.0 & 124.2 & 207.1 \\
\hline
\end{tabular}

Simulations presented by M. Li et al. in [8] were reproduced in order to compare M. Li et al. results with the upcoming simulations. As in M. Li et al. model [8], free nodes displacements are allowed only in the pipe axial direction for pipe surface (surface with chequered pattern, Fig. 5). To obtain consistent results, it was necessary to constrain tungsten by fixing point A (Fig. 5). This boundary condition was used for each upcoming simulation. In realistic condition, tungsten blocks are either mechanically constrained or free at the block bottom surface. In future, simulations should be performed by fixing the whole bottom surface of tungsten block. In this way conservative study will be achieved due to an increase of stress and strain in the tungsten block. Moreover, it is assumed that residual stresses generated in tungsten block during the manufacturing process are fully released over the first thermal cycles.

\section{Finite element results}

\subsection{Temperature field}

Thermal loadings at $20 \mathrm{MW} / \mathrm{m}^{2}$ involve strong temperature gradient in tungsten $\left(1674^{\circ} \mathrm{C}\right)$ on a thickness of $6.5 \mathrm{~mm}$. Indeed, temperature of $2132{ }^{\circ} \mathrm{C}$ is reached at the loaded surface and $458{ }^{\circ} \mathrm{C}$ is reached at tungsten to $\mathrm{Cu}$-OFHC interface (Fig. 7).

\subsection{Mechanical response}

Maximum plastic strains are expected to be observed in the center of the block where the maximum temperature gradient is located (point B, Fig. 4). Indeed, during experimental campaigns, this region corresponds to macro crack opening location [2]. Mechanical model used in simulations stabilized quickly. Indeed, Fig. 8 highlights the evolution of the equivalent plastic strain at point B (Fig. 5) for simulation Ref. After 4 thermal cycles, mechanical response becomes stable. Same quantitative observation is obtained for all performed simulations. Consequently, following mechanical results are the ones obtained at the 5th cycle. Equivalent plastic strain increment $\left(\Delta \varepsilon_{p}\right)$ is estimated for each simulation in order to perform lifetime calculations. $\Delta \varepsilon_{p}$ corresponds to half of the plastic strain generated over the 5th thermal cycle [8]. For the different simulations, $\Delta \varepsilon_{p}$ is summarized in Table 4. Fig. 9 shows the evolution of plastic strain over the 5 th thermal cycle for each simulation.

\subsubsection{Raw tungsten}

According to transient calculations, $\Delta \varepsilon_{p}$ is equal to $0.069 \%$ for 


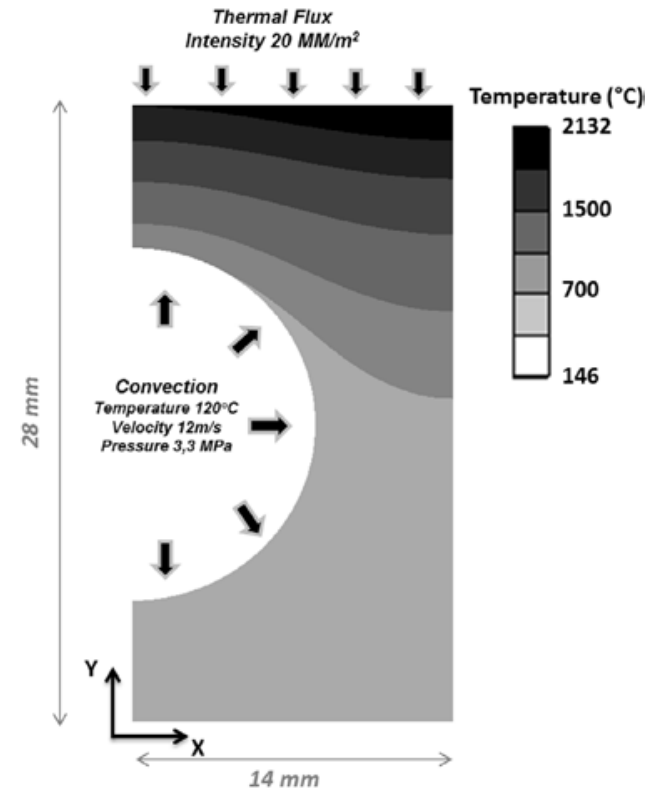

Fig. 7. Tungsten temperature at $20 \mathrm{MW} / \mathrm{m}^{2}$.

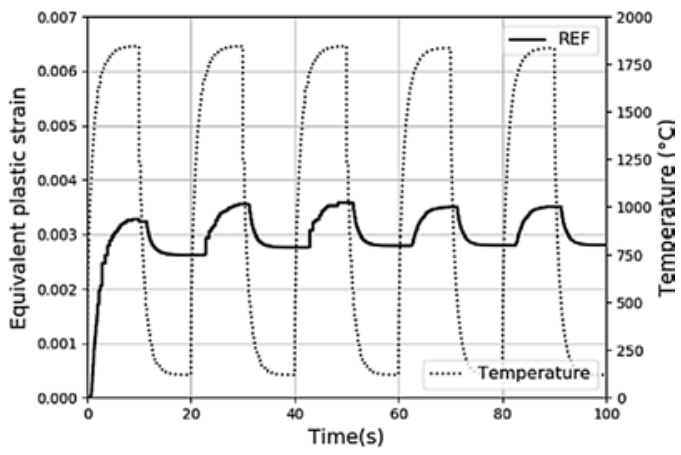

Fig. 8. Plastic strain and temperature for Ref simulation at point B.

Table 4

Equivalent plastic strain increments $\left(\Delta \varepsilon_{p}\right)$ obtained for each simulation after 5 th thermal cycle.

\begin{tabular}{|c|c|c|c|c|c|}
\hline & Ref & SR & $\begin{array}{l}\mathrm{RXX} \\
\text { thickness } 2\end{array}$ & $\begin{array}{l}\mathrm{RXX} \\
\text { thickness } 4\end{array}$ & $\begin{array}{l}\mathrm{SR} \\
+\mathrm{RXX}\end{array}$ \\
\hline Strain rate $\left(\mathrm{s}^{-1}\right)$ & $6 \times 10^{-3}$ & $6 \times 10^{-1}$ & $6 \times 10^{-3}$ & $6 \times 10^{-3}$ & $6 \times 10^{-1}$ \\
\hline$\Delta \varepsilon_{p}(\%)$ & 0.069 & 0.020 & 0.506 & 0.585 & 0.587 \\
\hline
\end{tabular}

simulation Ref and $0.020 \%$ for simulation SR (Table 4). These reveal that strain rate has an important effect on the mechanical plastic strain estimation for raw tungsten.

\subsubsection{Recrystallized tungsten}

Between RXX thickness 4 and M. Li et al. simulations [8], the only change is the mechanical tungsten behaviors inputs. Comparing $\Delta \varepsilon_{p}$ obtained for the RXX thickness 4 simulation $(0.585 \%)$, with the ones obtained by M. Li et al. [8] $(0.325 \%$.), one can note that use of the actual elastic-plastic behavior of recrystallized tungsten involves important $\Delta \varepsilon_{p}$ difference (nearly twice higher). As presented by M. Li et al. [8], Fig. 9 reveals that tungsten recrystallization thickness play an important role on the evolution of material plastic strain. Indeed, $\Delta \varepsilon_{p}$ obtained for Ref simulation is about seven times lower than the one obtained for simulation RXX thickness 2 and about eight times lower than the one obtained for simulation RXX thickness 4 . According to Fig. 9, $\Delta \varepsilon_{p}$ is equal to $0.585 \%$ for $\mathbf{R X X}$ thickness 4 simulation and

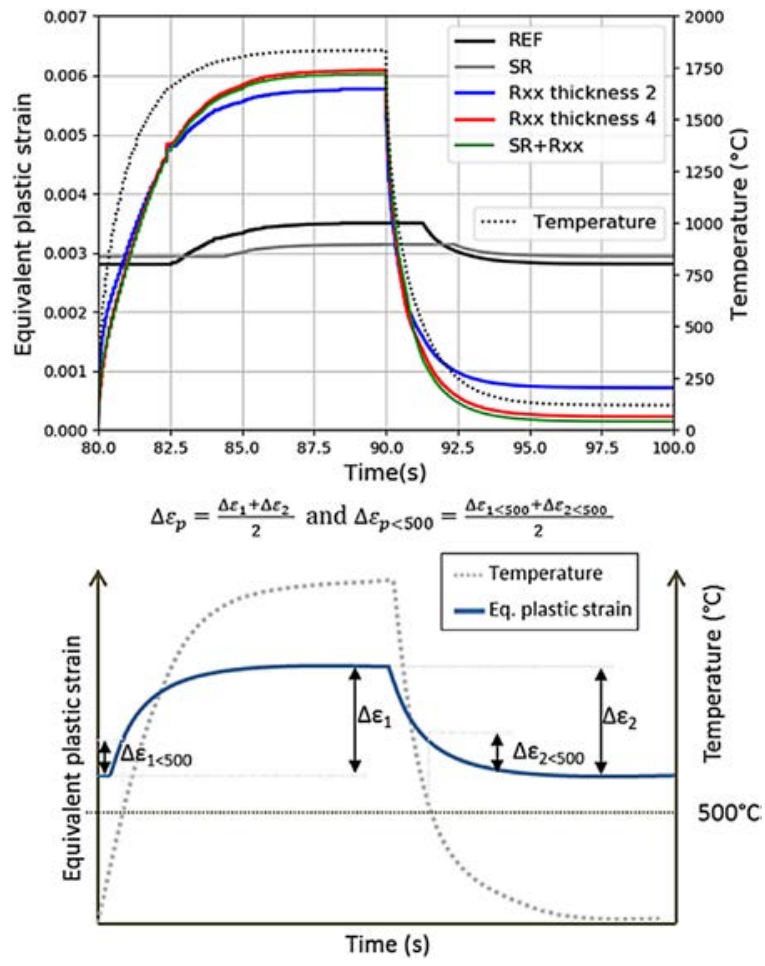

Fig. 9. Evolution temperature and equivalent plastic strain occurring for each simulation at the 5 th thermal cycle at point B.

$0.587 \%$ for $\mathbf{S R}+\mathbf{R X X}$ simulation (Table 4 ). These reveal that, strain rate has marginal effect on the estimation of the equivalent plastic strain increment for recrystallized tungsten.

\section{Discussion on lifetime prediction}

In order to optimize the use of plasma facing components in thermonuclear reactors and so ensure the mechanical vacuum chamber integrity over plasma shocks, numerical life time prediction has to be performed. In the literature, experiments are commonly performed to link equivalent plastic strain increments $\left(\Delta \varepsilon_{p}\right)$ directly to number of cycles to failure $\left(N_{f}\right)$ [18]. Manson-Coffin power law is used to estimate lifetime [19]. Low cycle fatigue data are available for several tungsten grades.

Methodology and data used to compute the component fatigue lifetime referred to the work of M. Li et al. This is based on the observation that the low cycle fatigue lifetime of tungsten at $815^{\circ} \mathrm{C}$ is greater than at room temperature. This is usually assumed as a consequence of the Ductile to Brittle Transition Temperature (DBTT). Hence it is considered that low cycle fatigue data at room temperature are relevant to estimate fatigue lifetime below the DBTT and that low cycle fatigue data at $815^{\circ} \mathrm{C}$ are relevant above. Here, three MansonCoffin relations displayed by M. Li et al. [8] are used. Two of them are given for raw tungsten (stress-relieved) at two different temperatures $\left(23^{\circ} \mathrm{C}\right.$ and $815^{\circ} \mathrm{C}$ ) and the third one is given for recrystallized tungsten (annealed) at $815^{\circ} \mathrm{C}$. Although, these are not corresponding to the studied tungsten grade, these experimental data are used in this paper in order to estimate lifetime. Moreover, to obtain Manson-Coffin relationships, fatigue tests were performed at isothermal temperature. According to Fig. 9 and M. Li et al. [8], equivalent plastic strain increments obtained for each simulation is generated during transient temperature phase. The use of this low cycle fatigue data is a strong assumption, however, because of the lack of experimental anisothermal data, available isothermal Manson-Coffin relations are used in this paper.

To study the effect of the DBTT on components life time, numbers of 
Table 5

Numerical life time prediction assuming DBTT at $500{ }^{\circ} \mathrm{C}$.

\begin{tabular}{llllll}
\hline & Ref & SR & $\begin{array}{l}\text { RXX } \\
\text { thickness } 2\end{array}$ & $\begin{array}{l}\text { RXX } \\
\text { thickness } 4\end{array}$ & $\begin{array}{l}\text { SR } \\
+ \text { RXX }\end{array}$ \\
\hline $\begin{array}{llllll}\Delta \varepsilon_{p}<500 \\
N_{1<500}\end{array}$ & 47 & 49 & 15 & 14 & 15 \\
$N_{2>500}$ & 884 & 44,197 & 52 & 36 & 29 \\
$N_{f 500}$ & $2,816,290$ & $44,635,406$ & 5892 & 3130 & 3227 \\
\hline
\end{tabular}

$\Delta \varepsilon_{p<500}$ : part of $\Delta \varepsilon_{p}$ which appeared bellow the DBTT (\%) fixed at $500{ }^{\circ} \mathrm{C}$. $N_{1}<500$ : number of cycles to failure obtained below the DBTT fixed at $500{ }^{\circ} \mathrm{C}$. $N_{2}>500$ : number of cycles to failure obtained above the DBTT fixed at $500^{\circ} \mathrm{C}$. $N_{f 500}$ : final life time estimation assuming DBTT at $500{ }^{\circ} \mathrm{C}$.

Table 6

Numerical life time prediction assuming DBTT at $350{ }^{\circ} \mathrm{C}$.

\begin{tabular}{|c|c|c|c|c|c|}
\hline & Ref & SR & $\begin{array}{l}\text { RXX } \\
\text { thickness } 2\end{array}$ & $\begin{array}{l}\text { RXX } \\
\text { thickness } 4\end{array}$ & $\begin{array}{l}\text { SR } \\
+\mathrm{RXX}\end{array}$ \\
\hline$\Delta \varepsilon_{p}<350(\%)$ & 26 & 49 & 8 & 8 & 8 \\
\hline$N_{1}<350$ & 5835 & 44,197 & 430 & 289 & 224 \\
\hline$N_{2}>350$ & $1,388,509$ & $44,635,406$ & 4227 & 2289 & 2315 \\
\hline$N_{f 350}$ & 5811 & 44,153 & 390 & 256 & 204 \\
\hline
\end{tabular}

$\Delta \varepsilon_{p}<350$ : part of $\Delta \varepsilon_{p}$ which appeared bellow the DBTT (\%) fixed at $350{ }^{\circ} \mathrm{C}$. $N_{1}<350$ : number of cycles to failure obtained below the DBTT fixed at $350{ }^{\circ} \mathrm{C}$ $N_{2}>350$ : number of cycles to failure obtained above the DBTT fixed at $350^{\circ} \mathrm{C}$. $N_{f 350}$ : final life time estimation assuming DBTT at $350{ }^{\circ} \mathrm{C}$.

cycles to failure calculations are performed at two different DBTTs $\left(350^{\circ} \mathrm{C}\right.$ and $\left.500{ }^{\circ} \mathrm{C}\right)[12,13]$. In this manner, part of $\Delta \varepsilon_{p}$ generated above the DBTT are used to estimate number of cycles to failure $\left(N_{2}\right)$ with the related Manson-Coffin relations obtained at $815^{\circ} \mathrm{C}$ (annealed for recrystallized and stress relieved for raw tungsten) and the part of $\Delta \varepsilon_{p}$ generated below the DBTT will be used to estimate number of cycles to failure $\left(N_{1}\right)$ with the Manson-coffin relation obtained at $23{ }^{\circ} \mathrm{C}$. Then, thanks to the following relation (equation (4)), related $N_{1}$ and $N_{2}$ are used to estimate final number of cycles to failure $\left(N_{f}\right)$ [8]:

$\frac{1}{\mathrm{Nf}}=\frac{1}{N 1}+\frac{1}{N 2}$

For simulations RXX thickness 2, RXX thickness 4 and SR $+\mathrm{RXX}$, Fig. 9 shows that during transient (heating and cooling) phases, part of $\Delta \varepsilon_{p}$ appears below DBTTs. This can be explained due to the use of low yield stresses for recrystallized tungsten. Recrystallized tungsten low yield stresses promote plasticity in the tungsten block. Plastic strain are involved throughout the thermal cycle at equivalent amplitude during the heating and the cooling phase leading to $98 \%$ released of plastic strain at the end of the thermal cycle. On the other hand, no plastic strain occurs below DBTTs during the heating phase for Ref and SR simulations. This reveals that quantitatively, cooling phase has stronger impact on the monoblock damage process. Off-set and time delays observed for simulations Ref and SR are explained by the use of high yield stresses of the raw tungsten.

Table 5 and Table 6 summarize related numbers of cycles to failure obtained for each simulation. Component lifetime is drastically reduced due to recrystallization. Also, tungsten thickness recrystallized layer play a role on the component life time. In this way, recrystallization phenomenon will be investigated further in the future to better define and model this phenomenon. Besides, Table 5 and Table 6 reveal an effect of DBTT on components lifetime for simulations providing important $\Delta \varepsilon_{p}$. Indeed, for the simulation $\mathbf{R X X}$ thickness 2 , component life time reduces significantly from 390 to 52 cycles. In future, the actual DBTT of rolled tungsten should be consequently accurately defined.

In the past, high heat flux experimental campaigns achieved and revealed that macro crack appears in tungsten block after a few tens (up to a few hundreds) of thermal cycles depending on tungsten supplier, geometry (width, tungsten thickness), and experimental coolant conditions [3]. Although numerical model used in this paper are not exactly corresponding to the experimental cases presented in [3], number of cycles to failure $\left(N_{f}\right)$ obtained in upcoming calculations are compared. In the case of RXX thickness $\mathbf{2}$, calculated number of cycles to failure is consistent to the one observed experimentally for the same recrystallized layer condition at the center of the block [2]. Preliminary study is performed in this paper to highlight the effect of tungsten recrystallization and tungsten viscoplasticity on lifetime estimation. Simulations are performed assuming (or not) recrystallized tungsten layer on the upper part of the block and using mechanical property obtained either at $6 \times 10^{-3} \mathrm{~s}^{-1}$ or $6 \times 10^{-1} \mathrm{~s}^{-1}$. According to M. Li et al. [8], the state of the material (recrystallized or raw material) plays a major role on the equivalent plastic strain increment. Regarding strain rate effect, the smaller the equivalent plastic strain increment, the higher the strain rate influence. Future simulations should be performed using dedicated mechanical model able to account for tungsten recrystallization and actual elastic-viscoplastic behavior of raw tungsten and recrystallized tungsten, even though tungsten viscoplasticity would have a marginal effect.

\section{Conclusion}

This paper proposes to estimate tungsten armoured component life time taking into account actual mechanical behavior of raw and recrystallized tungsten. For that, compressive tests were performed at several temperatures from $500{ }^{\circ} \mathrm{C}$ to $1150{ }^{\circ} \mathrm{C}$ and at several strain rates from $6 \times 10^{-1} \mathrm{~s}^{-1}$ to $6 \times 10^{-3} \mathrm{~s}^{-1}$. Raw tungsten tests reveal an elastic-plastic behavior that is sensitive to strain rate. Concerning recrystallized tungsten, it showed an elastic-viscoplastic behavior on the entire explored temperature range. This behavior was described by an elastic-plastic model with kinematic hardening constitutive relation in the modeling. Up to now, in the literature, mechanical behavior of tungsten and recrystallized tungsten were assumed as linear elastic and ideal-plastic using mechanical data displayed in [10]. Using mechanical behaviors experimentally obtained which are implemented in finite element modeling simulations; it shows that higher numbers of cycles to failure are obtained compared to previous simulations performed by M. Li et al. [8]. Moreover, simulations reveal that: recrystallization phenomenon and DBTT have major effect on the component life time whereas strain rate has marginal effect. Also, consistent life time estimations were obtained compared to the one observed experimentally in literature even if the exact boundary conditions (geometry, heat loading, cooling) are not exactly the same as the one which were simulated. These observations highlight that in the future, more accurate estimations could be performed by using dedicated mechanical model capable of taking into account the actual behavior of tungsten and modeling tungsten recrystallization phenomenon under thermal loadings.

\section{Acknowledgements}

The authors express their deep gratitude to Séverine Girard who performed compressive tests at Ecole Nationale Supérieure des Mines de Saint-Etienne. This work has received CEA funding from the "Programme Transverse de Compétence, Matériaux et Procédés" (PTCMP). This work has been carried out within the framework of the EUROfusion Consortium and has received funding from the Euratom research and training programme 2014-2018 under Grant Agreement No. 633053. The views and opinions expressed herein do not necessarily reflect those of the European Commission.

\section{References}

[1] K. Ezato, et al., Progress of ITER full tungsten divertor technology qualification in Japan, Fusion Eng. Des. 98-99 (2015) 1281-1284. 
[2] G. Pintsuk, et al., Characterization of ITER tungsten qualification mock-ups exposed to high cyclic thermal loads, Fusion Eng. Des. 98-99 (2015) 1384-1388.

[3] T. Hirai, et al., Status of technology R\&D for the ITER tungsten divertor monoblock, J. Nucl. Mater. 463 (2015) 1248-1251.

[4] T. Hirai, et al., Use of tungsten material for the ITER divertor, Nucl. Mater. Energy. 9 (2016) 616-622.

[5] P. Gavila, et al., High heat flux testing of mock-ups for a full tungsten ITER divertor, Fusion Eng. Des. 86 (9-11) (2011) 1652-1655.

[6] B. Riccardi, et al., Preliminary results of the experimental study of PFCs exposure to ELMs-like transient loads followed by high heat flux thermal fatigue, Fusion Eng. Des. 86 (9-11) (2011) 1665-1668.

[7] G. Pintsuk, et al., Qualification and post-mortem characterization of tungsten mockups exposed to cyclic high heat flux loading, Fusion Eng. Des. 88 (9-10) (2013) 1858-1861.

[8] M. Li, J.-H. You, Interpretation of the deep cracking phenomenon of tungsten monoblock targets observed in high-heat-flux fatigue tests at $20 \mathrm{MW} / \mathrm{m}^{2}$, Fusion Eng. Des. 101 (2015) 1-8.

[9] M. Li, J.-H. You, Structural impact of armor monoblock dimensions on the failur behavior of ITER-type divertor target components: size matters, Fusion Eng. Des. 113 (2016) 162-170.

[10] ITER Structural Design Criteria for In-vessel Components (SDC-IC) Appendix A: Materials Design Limit Data, G 74 MA 8 01-05-28 W 0.2, 2013.
[11] J. Du, et al., FEM study of recrystallized tungsten under ELM-like heat loads, J. Nucl. Mater. 463 (2015) 219-222.

[12] J. Reiser, et al., Tungsten foil laminate for structural divertor applications - tensile test properties of tungsten foil, J. Nucl. Mater. 434 (1-3) (2013) 357-366.

[13] J. Farre, et al., Étude de la transition fragile-ductile d' un tungstène, J. Phys. IV Colloq. 07 (C3) (1997) C3-879-C3-884.

[14] M. Wirtz, et al., Material properties and their influence on the behaviour of tungsten as plasma facing material, Nucl. Fusion 57 (6) (2017) 066018.

[15] M. Clavel, P. Bompard, Endommagement et rupture des matériaux - Volume 1, Hermes - Lavoisier, Traité MIM - Mécanique et ingénierie des matériaux, 2009, 350 pages.

[16] Forschungszentrum Karlsruhe, Nuclear Fusion Programme Annual Report of the Association Forschungszentrum Karlsruhe/EURATOM January 2006 - December 2006,Wissenschaftliche Berichte FZKA 7291 EUR 22705 EN.

[17] J. Schlosser, J. Boscary, Finite elements calculations for plasma facing components, proceedings of specialist workshop on high heat flux component cooling, Grenoble (1993).

[18] K.V.U. Praveen, V. Singh, Effect of heat treatment on Coffin-Manson relationship in LCF of superalloy IN718, Mater. Sci. Eng. A 485 (1) (2008) 352-358.

[19] ITER Material Properties Handbook, ITER Document No. S 74 MA 2.

[20] W. Prager, The theory of plasticity: a survey of recent achievements, Proc. Inst. Mech. Eng. 169 (1) (1955) 41-57. 